\title{
Making Travel to Cuba Work for Health and Sustainable Development
}

\begin{abstract}
Conner Gorry MA
In 2015, a record-breaking 3.5 million visitors-1 million from Canada alone-traveled to Cuba to explore its history, culture, natural splendor, and visit family. That same year, US President Barack Obama relaxed travel restrictions, giving general authorization for a dozen categories of legal travel by US citizens and residents. As a result, US visitors to the island ballooned by $80 \%$ between January 2015 and June 2016. And the numbers keep growing: the latest data show that foreign arrivals reached 4 million in 2016.[1] The surge in visitors highlights the potential negative impact of tourism on a developing country's infrastructure, environment, cultural patrimony and local economy-all considered important social determinants of health.
\end{abstract}

In response, an alliance of 100 US institutions, organizations, travel agencies and individuals have founded RESPECT (Responsible and Ethical Cuba Travel) to promote mutually beneficial travel policies and align Cuba with the global sustainable travel movement. RESPECT brings together multisector actors, including environmental, artistic, academic, legal, medical, religious and social justice organizations, as well as Cuban Americans, to work towards "supporting Cuba's goal to become a sustainable destination for mutual learning and benefit."[2] Emphasizing global citizenship, the 17 principles that RESPECT members uphold-and which they encourage all travelers to embrace-include learning about Cuba's rich natural, cultural and political history through readings and documentaries (especially those produced by Cubans) before visiting the island; respect for all Cuban people regardless of gender, sexual orientation, skin color, ability, religion, age, economic status or political persuasion; observing local laws (including condemning sex tourism, which violates not only ethical standards but also Cuban law); protecting the environment and conserving water and energy throughout their stay; supporting local craftspeople and artists; and helping to keep infectious disease from Cuba's shores.

Why is an association like RESPECT needed? Consider the most basic of travelers' needs, such as drinking water.

No one wants stomach problems disrupting their foreign vacation or business trip. Whether you travel to a neighboring country or around the globe, common sense argues: "don't drink the water." Most visitors default to drinking bottled water, but in an island ecology visited by four million people a year, this is an environmental disaster waiting to happen. While the Cuban government maintains recycling centers and Cubans have been accustomed to recycling and reusing since the economic crash of the 1990s, the volume of plastic generated by so many visitors will eventually overwhelm the island's landfill capacity - a dilemma faced by other popular island destinations such as Hawaii. Of course, it's important to stay hydrated in Cuba's heat, but rather than buy scores of half-liter bottles of water during a visit, travelers might try a different, more sustainable, approach: pack a water filter or water-purifying tablets or drops (the latter sold as hipoclorito de sodio in Cuban pharmacies); rent accommodation with a kitchen and boil your drinking water; or purchase 5-liter jugs of bottled water, replenishing a refillable bottle as needed.
If you're not familiar with the term experiential trave/—where visitors participate in a culture and get to know the people, rather than just observing and photographing them-it is rewarding for all involved and encapsulates RESPECT's principles for sustainable, crosscultural learning and community building. Volunteering is one of the most obvious facets of this concept (Global Volunteers has offered unique volunteer opportunities in Cuba for over a decade), but taking a cooking or dance class can serve similar ends. This past summer, scores of Cubans participated in the International Coastal Cleanup, a global one-day effort to clean up shorelines around the world and educate participants about environmental stewardship. Sponsored by Ocean Conservancy and Ocean Doctor, with their local counterpart, Cuba's National Aquarium, volunteers collected over 200 kilograms (441 pounds) of garbage from Havana's shoreline bordering the aquarium. The volume of beer cans and juice boxes, cigarette butts and straws collected in just two hours served as a crash course in the fragility of Havana's coasts, while providing participants a proactive, rewarding experience. But you don't need to wait for 2017's Coastal Cleanup to contribute: grab some bags and a few friends and collect litter from your favorite stretch of Cuban shoreline. This leading by example is another way visitors can help-if you've been to the island, you know what litterbugs some Cubans can be.

"Lead by example" is a good adage for responsible, respectful travel. "Do no harm," the medical principle specifically invoked in RESPECT's guiding document, is another. The hiker's creed, "leave no trace," is a third. And if you're in a field such as health or environmental sciences, a fourth could be added: "take cooperation home." That is, use your trip to explore avenues to meet Cubans in your line of work and interest, opening the door to long-term cooperation that benefits people in both countries. Cancer and vaccine research, health strategies against infectious and other diseases, renewable energy, and protection of shared marine resources are just some of the possibilities for interinstitutional collaboration. And these are often sparked by the passion of first-time visitors to Cuba, who build on respectful engagement to form lasting partnerships.

The first step we can all take is traveling consciously, joining with Cubans as global citizens to forge a healthier, more sustainable future for the island Columbus called "the most beautiful land human eyes have ever seen." - 1 -

1. AFP. Cuba alcanza record de 4 millones de turistas en 2016. El Tiempo [Internet]. 2016 Dec 31 [cited 2017 Jan 14]. [About 1 screen]. Available from www .eltiempo.com/mundo/latinoamerica. Spanish.

2. RESPECT. 100 US Institutions and Travel Organizers Found RESPECT (Responsible and Ethical Cuba Travel). 16 Dec 2016.

Submitted: December 30, 2016

Approved for publication: January 15, 2017

Disclosures: The author, Senior Editor of MEDICC Review, has written over 20 travelers' guidebooks and is a founding member of RESPECT. Correspondence: connergo@ekit.com 